\title{
A Method for Rapid Measurement of Heat or Cold Resistance of Small Insects
}

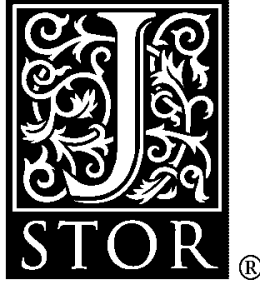

\author{
R. B. Huey; W. D. Crill; J. G. Kingsolver; K. E. Weber \\ Functional Ecology, Vol. 6, No. 4 (1992), 489-494.
}

Stable URL:

http://links.jstor.org/sici?sici=0269-8463\%281992\%296\%3A4\%3C489\%3AAMFRMO\%3E2.0.CO\%3B2-K

Functional Ecology is currently published by British Ecological Society.

Your use of the JSTOR archive indicates your acceptance of JSTOR's Terms and Conditions of Use, available at http://www.jstor.org/about/terms.html. JSTOR's Terms and Conditions of Use provides, in part, that unless you have obtained prior permission, you may not download an entire issue of a journal or multiple copies of articles, and you may use content in the JSTOR archive only for your personal, non-commercial use.

Please contact the publisher regarding any further use of this work. Publisher contact information may be obtained at http://www.jstor.org/journals/briteco.html.

Each copy of any part of a JSTOR transmission must contain the same copyright notice that appears on the screen or printed page of such transmission.

JSTOR is an independent not-for-profit organization dedicated to creating and preserving a digital archive of scholarly journals. For more information regarding JSTOR, please contact support@jstor.org. 


\title{
A method for rapid measurement of heat or cold resistance of small insects
}

\author{
R. B. HUEY, W. D. CRILL, J. G. KINGSOLVER and K. E. WEBER* \\ Department of Zoology NJ-15, University of Washington, Seattle, Washington 98195 and *Department of \\ Biological Sciences, University of Southern Maine, Portland, Maine 04103, USA
}

\begin{abstract}
Summary
1. We describe a new technique for rapidly measuring the heat or cold resistance of many small insects. We heat (or cool) insects in a temperature-controlled column and measure the temperature at which they are knocked down.

2. An artificial selection experiment on heat resistance demonstrates that knockdown temperatures respond rapidly to selection. After only four generations of selection, the experimental and control lines differed significantly in both knockdown temperature and physiological heat tolerance, as measured by per cent survival of a heat shock.
\end{abstract}

3. Potential applications (acclimation, ageing, selection) and technical problems (body size, humidity, statistical considerations) are evaluated.

Key-words: Drosophila, mass selection, thermal sensitivity

Functional Ecology (1992) 6, 489-494

\section{Introduction}

Measures of tolerance to extreme heat or cold are widely used in physiological ecology and in evolutionary physiology (Cowles \& Bogert 1944; Paladino et al. 1980; Prosser 1986; Hoffmann \& Parsons 1991). These delimit the range of body temperatures that species or populations can survive (Fry 1957); and, to the extent that they correlate with 'optimal' performance temperatures (Becker \& Genoway 1979; Garland, Huey \& Bennett 1991), they serve also as convenient and ecologically relevant indices of overall thermal sensitivity (Huey 1982; Hoffmann \& Parsons 1991).

In studies with lower vertebrates and some large insects (Heath \& Wilkin 1970; Becker \& Genoway 1979; Paladino et al. 1980); tolerance to extreme temperature is often assessed by heating (or cooling) an animal until it loses its righting response (Cowles \& Bogert 1944) or goes into spasms (Hutchison 1961). These 'critical thermal maximum' ('minimum') temperatures are easily measured, and the tested animals usually survive.

In studies with small insects, however, critical body temperatures cannot be measured directly because such insects are too small (Krogh 1948). Consequently, heat tolerance of small insects is usually measured by exposing groups to a high (or low) ambient temperature for a set period [e.g. $39 \cdot 5^{\circ} \mathrm{C}$ for
Coyne, Bundgaard \& Prout 1983) or $-3 \cdot 0^{\circ} \mathrm{C}$ for $24 \mathrm{~h}$ (Davidson 1990)], waiting 24h, and then determining the percentage of individuals that survived. If percentage survival is measured over a range of temperatures or times of exposure, a $\mathrm{LD}_{50}$ can be estimated (Kimura 1988; Quintana \& Prevosti 1990). Nevertheless, these widely used techniques have significant disadvantages: many test animals are killed and the survivors are sometimes sterilized (David et al. 1983; but see White et al. 1970; Parsons 1980). Consequently, per cent survival techniques may be unsuitable for studies of quantitative genetics or of responses to artificial selection, unless indirect 'family' analyses are used (Morrison \& Milkman 1978; Kilias \& Alahiotis 1985; Quintana \& Prevosti 1990). Moreover, repeatability can be low (Coyne et al. 1983; Huey, Partridge \& Fowler 1991); and the technique yields populational rather than individual statistics, so that statistical power is reduced.

We have developed an efficient new way to measure the temperature tolerance of many small insects (e.g. parasitic wasps, Drosophila). We measure temperatures ('knock-down temperatures' $=T_{\mathrm{kd}}$ ) at which such insects are incapacitated by acute exposure to heat or cold. These temperatures correspond to the 'critical' temperatures measured in lower vertebrates (Paladino et al. 1980). In studies with $D$. melanogaster Meigen, we simultaneously measure knock-down temperatures on large numbers of flies ( 1000 or more) and have found that 
490

R. B. Huey et al.

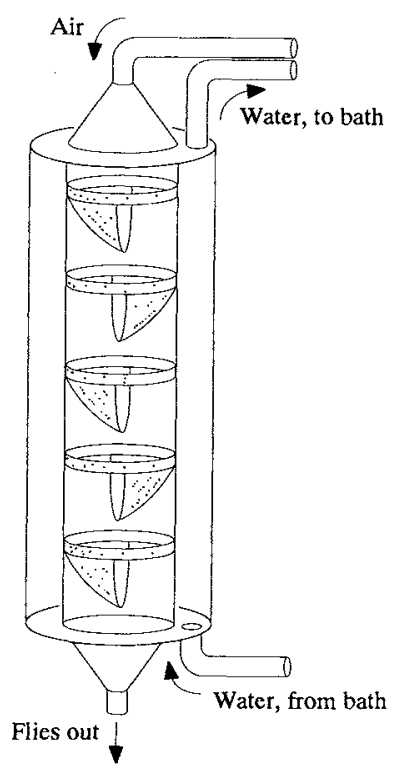

Fig. 1. Apparatus for measuring and 'fractionating' small arthropods by knock-down resistance to heat or cold. The study animals are first put into the top of the column, and the temperature within the column then warmed (or cooled) by pumping water (ethylene glycol) from a temperaturecontrolled bath through the surrounding water jacket. When the animals reach an incapacitating body temperature (knock-down temperature), they fall out of the column into collecting vials below. Knock-down temperatures of small insects are closely approximated (see Appendix) by measuring air temperature within the column.

measurement does not affect the viability or fertility of the flies. Thus this technique should facilitate quantitative genetic and selection experiments. Moreover, it should be useful in diverse studies of the thermal biology of small arthropods. Here we describe the apparatus and experimental protocols involved in measuring knock-down temperatures and discuss pilot applications and potential limitations.

\section{Materials and methods}

We index heat (or cold) resistance as the temperature at which insects are incapacitated by extreme heat (or cold). In brief, the insects are heated (or cooled) at a controlled rate in a water-jacketed glass column. At some limiting temperature insects become incapacitated and fall out of the bottom of the column into collecting tubes. Because small insects have short thermal time constants (Stevenson 1985), their body temperature will closely track ambient air temperatures in the column (Appendix). Consequently, by monitoring the ambient temperature inside the column and by changing collecting tubes at predetermined intervals of temperature change (e.g. $0.5^{\circ} \mathrm{C}$ ), we rapidly and simultaneously measure the knock-down temperatures for large numbers of insects, and the insects are automatically fractionated (i.e. separated into phenotypic classes) by knockdown temperatures.

\section{HEAT RESISTANCE}

To measure knock-down temperatures, we have modified an apparatus developed originally (Weber 1988; Weber \& Diggins 1990; see also Cohan \& Graf 1985; Hoffmann \& Cohan 1987) to study knockdown resistance of flies to ethanol and other vapours. The column consists of a water-jacketed, glass cylinder $120 \times 7.5 \mathrm{~cm}$, with internal baffles (Fig. 1; details in Weber 1988). In our pilot studies with Drosophila, we initially set the temperature of the column at $30^{\circ} \mathrm{C}$, a warm but not disabling temperature. Flies are then introduced at the top of the column, where they tend to remain (they are negatively geotropic). Fine-mesh baffles in the column provide extensive perches for the flies and increase the efficiency of fractionation (Weber 1988), while allowing air currents (see below) to pass through the column with only limited resistance. The temperature of the water jacket is then raised at a set rate $\left(c .0 .5^{\circ} \mathrm{C} \mathrm{min}^{-1}\right)$ by heating water in the adjacent bath, and rapidly circulating water through the water jacket. The increasingly warm water in the jacket heats the air and flies inside the column. When flies reach their critical temperature, they fall through the baffles, out through a fluon-coated funnel at the bottom of the column, and into a narrow fluon-coated collecting tube (at room temperature) from which they cannot escape. We change collecting tubes every $0.5^{\circ} \mathrm{C}$ and subsequently sex and count the flies in each tube. [If sexing is not required, falling insects can efficiently be counted electronically by placing a photocell detector between the column and the collecting tubes (Weber 1988).] Data from a sample run are shown in Fig. 2.

To reduce thermal gradients within the column (e.g. top to bottom, wall to centre) and to reduce the thermal time constant of the flies (see below), we pump air (equilibrated to the temperature of the water jacket) through the column from top to bottom. [Incurrent air is passed first through a copper

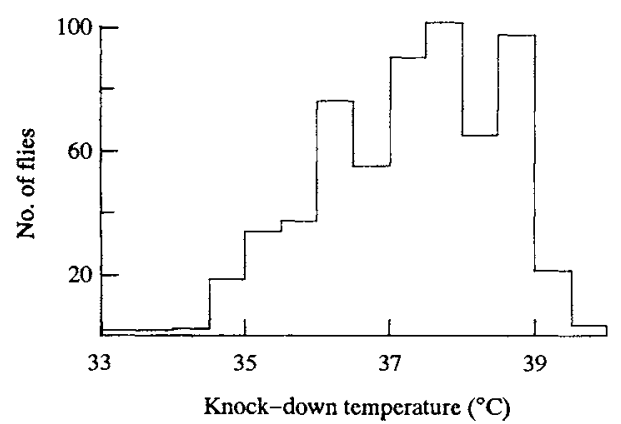

Fig. 2. A histogram of frequency of upper knock-down temperatures for a sample $(n=602)$ of male Drosophila melanogaster. 
Measuring insect thermal resistance

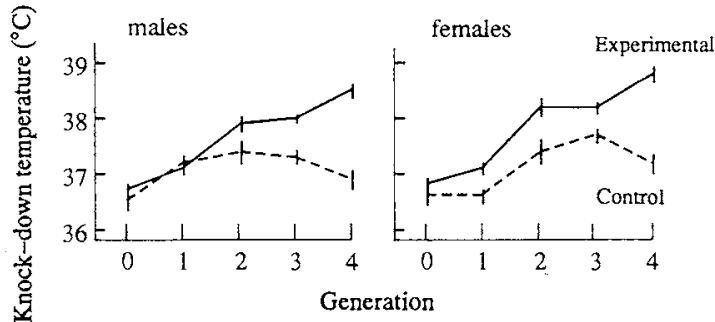

Fig. 3. Mean knock-down temperatures ( $\pm 1 \mathrm{SE}$ ) of males from selected and control lines of Drosophila melanogaster at generations 0 through 4 of selection (top $25 \%$ ) on knock-down resistance to heat. Knock-down temperatures $\left(T_{\mathrm{kd}}\right)$ responded rapidly to selection, such that $T_{\mathrm{kd}}$ of the selected line increased by about $1.5^{\circ} \mathrm{C}$ relative to that of the control line.

coil in the water-bath and then runs counter-current beside the excurrent water line and inside a common insulative sheath.] Air flow can be adjusted to minimize intracolumn gradients. At low flow rates $\left(0.5\right.$ litres $\left.\min ^{-1}\right)$, the time constant of insects the size of $D$. melanogaster is about $20 \mathrm{~s}$.

Fractionation is fast: in approximately $20 \mathrm{~min}$, we can fractionate over 1000 flies according to their critical temperature. Consequently, rapid àcelimation (Czajka \& Lee 1990), heat-shock responses (Huey \& Bennett 1990), or desiccation (Maynard Smith 1956) should not confound our measurements. However, humidified or dehumidified air can be passed through the column, if appropriate (see below).

Alternatively, the water jacket could be set at a constant high (or low) temperature and then the length of time measured before the insects were knocked down. The resulting data would be directly equivalent to those in studies of resistance to ethanol vapours (e.g. Weber 1988). However, if times are long, this measure of heat resistance might be confounded by rapid acclimation (Czajka \& Lee 1990).

\section{COLD RESISTANCE}

To measure lower knock-down temperatures, we replace the water in the system with ethylene glycol, and use a cooling coil in the water-bath to lower the temperature from $15^{\circ} \mathrm{C}$ until the flies fall out of the column. Unless the cooling coil is powerful enough to cool the column quickly, rapid acclimation (Czajka \& Lee 1990) could confound the measurements. Cooling rates can also be increased by placing the entire apparatus in a cold room and by reducing the fluid volume (i.e. using a small column and water-bath). To prevent water (which can trap flies) from condensing on the walls of the column during cooling, incurrent air can be passed through a desiccator on its way to the column. Because evaporation in dry air is minimal at low air temperatures, dry air is unlikely to influence estimates of lower knock-down temperatures.

\section{Validation}

Knock-down temperatures may reflect actual differences either in physiological heat (or cold) resistance or, possibly, in the behavioural willingness of flies to 'hang on' when confronted with a rapidly changing thermal environment. In the latter case the insects would be falling out at temperatures below their true critical temperatures. Two observations demonstrate that our technique does index true physiological heat or cold tolerance (i.e. ability to survive a heat or cold shock). First, flies falling out of the column are generally incapacitated and thus are not 'jumping out' while still co-ordinated. For example, flies can walk slowly and hang on in the column at $7 \cdot 5^{\circ} \mathrm{C}$; but when cooled to $6.5^{\circ} \mathrm{C}$, they are unable to walk and start to fall out of the column in large numbers. Second, after four generations of artificial selection (described below) for high knock-down temperatures, flies from the selected line had significantly higher heat tolerance: only $5.6 \%$ of the control females survived an exposure of $39.5^{\circ} \mathrm{C}$ for $0.5 \mathrm{~h}$, whereas $36 \%$ of the selected females survived $(P<0.001)$. Thus, even if selection on knock-down temperatures is selecting on behaviour, it is also selecting on true physiological tolerance.

Knock-down exposure does not influence survival or sterility of Drosophila. For example, less than 1\% of flies in a test run died within $24 \mathrm{~h}$. Similarly, 11 males and 12 females were tested for fertility after being measured for upper knock-down temperature: all produced viable young.

\section{Sample applications}

Knock-down temperatures can readily characterize the heat and cold resistance of a species, population, or stock. Sample data of upper knock-down temperatures of $D$. melanogaster (originally collected from Brighton, UK; maintained for 6 years at $25^{\circ} \mathrm{C}$ ) are shown in Fig. 2.

Knock-down temperatures can also be used to study developmental or acclimation effects on heat and cold resistance. In a pilot study (Crill 1991), for example, knock-down temperatures of $D$. melanogaster were significantly affected not only by the temperatures flies experienced during development (egg to adult, 25 vs $18^{\circ} \mathrm{C}$ ), but also by the temperatures their parents experienced $\left(25 v s 18^{\circ} \mathrm{C}\right)$. The effects of age or of various environmental factors on knock-down temperatures could similarly be studied. 
Finally, because flies are neither killed nor sterilized by the treatment, knock-down temperatures should prove useful for quantitative genetics and for selection experiments. At the end of a four-generation experiment in which the top $25 \%$ of flies (experimental line, average $n=1251$ flies generation $^{-1}$ ) or a random $25 \%$ (control line) were used to found the next generation, the mean knock-down temperature of the experimental line had increased to $1.5^{\circ} \mathrm{C}$ above that of the control line, and no plateau in response was evident (Fig. 3). The increase was equivalent to about one standard deviation (phenotypic) of the control population. [The exact selection intensity is unknown. Selected males and females were kept together for 2-3 days before egg collections were made, so some remating may have occurred. Thus selection intensities were between 25 and $50 \%$. Assuming a $50 \%$ selection intensity (no remating), the realized heritability is $28 \%$.]

\section{Potential limitations and technical problems}

\section{BODY SIZE}

Because we assume that the air temperature in the column closely approximates insect body temperature, our technique will largely be limited to small arthropods (e.g. the size of Drosophila), for which time constants $(\tau)$ are very short (Stevenson 1985). For larger insects, however, the difference between $T_{\mathrm{b}}$ and $T_{\mathrm{a}}$ could be unacceptably large. Heat transfer analysis (Appendix) shows that the absolute maximum temperature difference $\left|T_{\mathrm{b}}-T_{\mathrm{a}}\right|$ is the product of $(b \tau)$, where $b$ is the rate of heating or cooling. The temperature differential can obviously be reduced either by slowing $b$ or by increasing air speed within the column, thus reducing $\tau$. For large insects at reasonable flow rates, $\tau$ may still be long, and body temperature could lag significantly behind measured air temperature. However, using a microprobe thermocouple in a hypodermic needle (e.g. Heinrich 1987), one can directly measure the body temperatures of large insects as they fall out of the column.

\section{HUMIDITY}

If evaporative water loss from the insects is high (Heinrich 1979; Toolson 1987), then $T_{\mathrm{b}}$ will tend to deviate below $T_{\mathrm{a}}$; and thus the $T_{\mathrm{a}}$ at which flies were knocked down would not be a close approximation of true $T_{\mathrm{b}}$. However, convective heat transfer is large enough in small insects (Stevenson 1985) to oppose this, such that evaporative cooling is unlikely to be an important confounding factor. Similarly, if heating rate is slow and if evaporative water loss is very high, then insects could be knocked down by desiccation, not by heat. This problem is probably unimportant: desiccation influences survival of Drosophila at high temperature (Parsons 1980), but only over time scales much longer than used in our experiments (Fig. 1 in Maynard Smith 1956). In any case, if desiccation is a potential problem, humidified air can be funnelled through the column. For example, incurrent air can be humidified by bubbling it through the water-bath or water jacket. To study the effects of humidity on knock-down resistance, experiments could be run at near $0 \%$ r.h., by passing incurrent air through a desiccator. In principle, humidity could be controlled at any desired level, even during dynamic heating, by bubbling air through a computer-controlled, auxiliary water-bath. Such studies would be of interest, especially as resistance to heat and desiccation are genetically correlated in D. melanogaster (Hoffmann \& Parsons 1989).

\section{THERMAL GRADIENTS WITHIN THE COLUMN}

Thermal gradients from top to bottom of the column can be reduced by increasing the flow rate of water in the jacket. Gradients from the wall to the centre can be reduced by narrowing the diameter of the chamber. Moreover, all gradients within the column can be minimized by increasing the flow rate of air through the chamber.

\section{STATISTICAL CONSIDERATIONS}

Because many flies are run simultaneously, knockdown temperatures for each fly in a given sample will not be statistically independent. This problem can be solved in several ways. If morphologically distinguishable species are being compared, both species can be run simultaneously through the column: any 'batch' effect is thus common to both species. If different treatment groups (e.g. acclimation groups) or populations are being compared, one or both groups could be marked (e.g. with a fluorescent dye), and again run simultaneously. In one pilot experiment, however, flies dusted with a dye had significantly higher $(P<0 \cdot 001)$ knock-down temperatures than did control flies, suggesting a risk of artefacts with this approach. When either approach is impractical, several batches (temporally randomized) should be run for each group, thus enabling one to estimate the magnitude of any batch effect.

\section{Acknowledgements}

We acknowledge support from NSF BSR 8718063 to RBH, BSR 8919600 to RBH and B. Sinervo, BSR 8908131 to JGK, and NIH 5-RO1.GM 21,179 to R. C. Lewontin. We thank Sandra Toba and Jon Herron for assistance and A. F. Bennett, A. Hoffmann, A. R. Kiester, and L. Partridge for constructive discussion, and two anonymous reviewers for helpful suggestions on the manuscript. We thank L. Partridge for access to her fly stocks. 
Measuring insect

thermal resistance

\section{References}

Becker, C.D. \& Genoway, R.G. (1979) Evaluation of the critical thermal maximum for determining thermal tolerance of freshwater fish. Environmental Biology of Fishes 4, 245-256.

Cohan, F.M. \& Graf, J.-D. (1985) Latitudinal cline in Drosophila melanogaster for knockdown resistance to ethanol fumes and for rates of response to selection for further resistance. Evolution 39, 278-293.

Cowles, R.B. \& Bogert, C.M. (1944) A preliminary study of the thermal requirements of desert reptiles. Bulletin of the American Museum of Natural History 83, 261-296.

Coyne, J.A., Bundgaard, J. \& Prout, T. (1983) Geographic variation of tolerance to environmental stress in Drosophila pseudoobscura. American Naturalist 122, 474-488.

Crill, W.D. (1991) High parental and developmental temperatures increase heat resistance of adult Drosophila melanogaster. American Zoologist (abstr.) 13, 58A.

Czajka, M.C. \& Lee, R.E., Jr. (1990) A rapid cold-hardening response protecting against cold shock injury in Drosophila melanogaster. Journal of Experimental Bio$\log y$ 148, 245-254.

David, J.R., Allemand, R., Van Herrewege, J. \& Cohet, Y. (1983) Ecophysiology: abiotic factors. The Genetics and Biology of Drosophila, vol. 3d (eds. M. Ashburner, H.L. Carson, \& J.N. Thompson), pp. 105-170. Academic Press, London.

Davidson, J.K. (1990) Non-parallel geographic patterns for tolerance to cold and desiccation in Drosophila melanogaster and D. simulans. Australian Journal of Zoology 38, 155-161.

Fry, F.E.J. (1957) The lethal temperature as a tool in taxonomy. Annales Biologiques 33, 205-219.

Garland, T., Jr, Huey, R.B. \& Bennett, A.F. (1991) Phylogeny and coadaption of thermal physiology in lizards: a reanalysis. Evolution 45, 1969-1975.

Heath, J.E. \& Wilkin, P.J. (1970) Temperature responses of the desert cicada, Diceroprocta apache (Homoptera, Cicadidae). Physiological Zoology 43, 145-154.

Heinrich, B. (1979) Keeping a cool head: honeybee thermoregulation. Science 205, 269-271.

Heinrich, B. (1987) Thermoregulation by winter-flying endothermic moths. Journal of Experimental Biology $127,313-332$

Hoffmann, A.A. \& Cohan, F.M. (1987) Genetic divergence under uniform selection. III. Selection for knockdown resistance to ethanol in Drosophila pseudoobscura populations and their replicate lines. Heredity $\mathbf{5 8}, 425-433$.

Hoffmann, A.A. \& Parsons, P.A. (1989) Selection for increased desiccation resistance in Drosophila melanogaster: additive genetic control and correlated responses for other stresses. Genetics 122, 837-845.

Hoffmann, A.A. \& Parsons, P.A. (1991) Evolution, Genetics and Environmental Stress. Oxford University Press, Oxford.

Huey, R.B. (1982) Temperature, physiology, and the ecology of reptiles. Biology of the Reptilia, Vol. 12, Physiology (C) (eds. C. Gans \& F.H. Pough), pp. 25-91. Academic Press, London.

Huey, R.B. \& Bennett, A.F. (1990) Physiological adjustments to fluctuating thermal environments: an ecological and evolutionary perspective. Stress Proteins in Biology and Medicine (eds. R. Morimoto, A. Tessieres \& C. Georgopoulous), pp. 37-59. Cold Spring Harbor Laboratory Press, Cold Spring Harbor, New York.

Huey, R.B., Partridge, L. \& Fowler, K. (1991) Thermal sensitivity of Drosophila melanogaster responds rapidly to laboratory natural selection. Evolution 45, 751-756.
Hutchison, V.H. (1961) Critical thermal maxima in salamanders. Physiological Zoology 34, 92-125.

Kilias, G. \& Alahiotis, S.N. (1985) Indirect thermal selection in Drosophila melanogaster and adaptive consequences. Theoretical and Applied Genetics 69, 645650.

Kimura, M.T. (1988) Adaptations to temperate climates and evolution of overwintering strategies in the Drosophila melanogaster species group. Evolution 42, 12881297.

Krogh, A. (1948) Determination of temperature and heat production in insects. Zeitschrift fuer Vergleichende Physiologie 31, 274-280.

Levins, R. (1969) Thermal acclimation and heat resistance in Drosophila species. American Naturalist 103, 483-499.

Maynard Smith, J. (1956) Temperature tolerance and acclimatization in Drosophila subobscura. Journal of Experimental Biology 34, 85-96.

Morrison, W.W. \& Milkman, R. (1978) Modification of heat resistance in Drosophila by selection. Nature, 273, 49-50.

Paladino, F.V., Spotila, J.R., Schubauer, J.P. \& Kowalski, K.T. (1980) The critical thermal maximum: a technique used to evaluate physiological stress and adaptation in fishes. Revue Canadienne de Biologie 9, 115-122.

Parsons, P.A. (1980) Parallel climatic races for tolerances to high temperature-desiccation stress in two Drosophila species. Journal of Biogeography 7, 97-101.

Prosser, C.L. (1986) Adaptational Biology: Molecules to Organisms. John Wiley \& Sons, New York.

Quintana, A. \& Prevosti, A. (1990) Genetic and environmental factors in the resistance of Drosophila subobscura adults to high temperature shock. Theoretical and Applied Genetics 80, 847-851.

Stevenson, R.D. (1985) Body size and limits of the daily range of body temperature in terrestrial ectotherms. American Naturalist 125, 102-117.

Toolson, E.C. (1987) Water profligacy as an adaptation to hot deserts: water loss rates and evaporative cooling in the Sonoran Desert cicada, Diceroprocta apache (Homoptera: Cicadidae). Physiological Zoology 60, 379-385.

Weber, K.E. (1988) An apparatus for measurement of resistance to gas-phase agents. Drosophila Information Service 67, 91.

Weber, K.E. \& Diggins, L.T. (1990) Increased selection response in larger populations. II. Selection for ethanol vapor resistance in Drosophila melanogaster at two population sizes. Genetics 125, 585-597.

White, E.B., DeBach, P. \& Garber, M.J. (1970) Artificial selection for genetic adaptation to temperature extremes in Aphytis lingnanensis Compere (Hymenoptera: Aphelinidae). Hilgardia 40, 161-192.

\section{Appendix}

We are interested in how the body temperature of an insect at time $t, T_{\mathrm{b}}(t)$, differs from ambient temperature in the column, $T_{\mathrm{a}}(t)$, as the column is heated or cooled. Consider a simple heat flux balance where the rate of heat storage $\left(q_{\mathrm{st}}\right)$ is balanced by the rate of heat transfer $\left(q_{\mathrm{c}}\right)$ as a result of convection and perhaps other mechanisms. Then:

$q_{\mathrm{st}}=q_{\mathrm{c}}$

$C m \mathrm{~d}\left[T_{\mathrm{b}}(t)\right] / \mathrm{d} t=h A\left[T_{\mathrm{a}}(t)-T_{\mathrm{b}}(t)\right]$

where $C=$ the specific heat of the insect, $m=$ body mass, $h=$ the heat transfer coefficient, and $A=$ the surface area for heat transfer. When convection is the dominant mode of heat transfer, as for small insects (Stevenson 1985), $h$ is determined primarily by the size and shape of the insect and by air flow velocity in the column. 
494

R. B. Huey et al.

Let the time constant $\tau=C m / h A$. Suppose that ambient temperature in the column changes linearly with time, so that $T_{\mathrm{a}}(t)=a+b t$, where $a$ is the initial temperature at time $t=0$, and $b$ is the rate of temperature increase in the column. Then:

$\mathrm{d}\left[T_{\mathrm{b}}(t)\right] / \mathrm{d} t=\left[a+b t-T_{\mathrm{b}}(t)\right] / \tau$

with initial condition $T_{\mathrm{b}}(0)=a$. The solution of this linear, first-order ODE is:

$T_{\mathrm{b}}(t)=a+b t-b \tau\left[1-\mathrm{e}^{(-t / \tau)}\right]$

Recalling that $T_{\mathrm{a}}(t)=a+b t$, then:

$T_{\mathrm{b}}(t)-T_{\mathrm{a}}(t)=-b \tau\left[1-\mathrm{e}^{(-t / \tau)}\right]$
Note that as $t$ approaches infinity, the temperature difference $T_{\mathrm{b}}(t)-T_{\mathrm{a}}(t)$ approaches $(-b \tau)$. Thus the lag of body temperature from ambient temperature is determined simply by the size, shape and mass of the insect and the air velocity in the column (determining $\tau$ ) and the rate of temperature change in the column $(b)$. For example, for Drosophila in our pilat experiments, $\tau=20 \mathrm{~s}$; and for a temperature rise of $10^{\circ} \mathrm{C} 15 \mathrm{~min}^{-1}, b=0.011^{\circ} \mathrm{C} \mathrm{s}^{-1}$. Thus the absolute maximum $\operatorname{lag}\left|T_{\mathrm{b}}(t)-T_{\mathrm{a}}(t)\right|$ is small $\left(0.22^{\circ} \mathrm{C}\right)$ but can easily be reduced by increasing the air flow rate; in our experiments the air flow rate was only $2.5 \mathrm{~mm} \mathrm{~s}^{-1}$.

Received 2 September 1991; revised 26 November 1991; accepted 16 December 1991 